\title{
RELAÇÕES DE PODER NO PROJETO DE ECONOMIA DE COMUNHÃO
}

\author{
Power Relations in the Economy Project Communion
}

Recebido em 08.08.09 / Aceito em 12.01.10

Guido Vaz Silva ${ }^{1}$ e Daniel Pacheco Lacerda ${ }^{2}$

\section{Resumo}

A pesquisa exploratória, aqui resumida, insere-se em um contexto de "crise" socioambiental. Tal "crise" encaminha a necessidade por mudanças transformadoras. Uma proposta de mudança, somada às já existentes, vem sendo investigada como uma forma alternativa de gestão: a Economia de Comunhão. Dentro desse tema, essa pesquisa se restringe a uma tentativa de análise do Poder nas empresas que adotam essa forma de gestão. Primeiramente, pesquisou-se, junto a empresários representativos, uma visão comum para caracterizar o objeto. Em seguida, realizou-se um estudo de caso em uma das principais empresas que se enquadram no conceito de Economia de Comunhão. O método de análise de conteúdo foi utilizado para a extração de ilações sobre o comportamento do fenômeno Poder nessas organizações. Os quadros analíticos produzidos sobre as entrevistas fornecem indícios que demonstram idiossincrasias nas formas de exercício do poder dessa nova proposta de gestão vis-à-vis as disseminadas amplamente no sistema produtivo. Tais evidências indicaram a influência decisiva dos pressupostos sustentadores do Projeto sobre as relações de poder, tornando possível uma prática organizacional próxima ao que se denomina paradigma radical humanista na teoria organizacional.

1 Doutorando do Programa de Pós-Graduação em Engenharia (Pesquisa Operacional e Gerência de Produção) da Universidade Federal do Rio de Janeiro (COPPE/UFRJ). E-mail: guido.vaz@gpi.ufrj.br

2 Doutorando do Programa de Pós-Graduação em Engenharia (Pesquisa Operacional e Gerência de Produção) da Universidade Federal do Rio de Janeiro (COPPE/UFRJ).E-mail: daniel.lacerda@gpi.ufrj.br 
Palavras-chave: Economia de Comunhão; Poder; Estudo de Caso; Novos Modelos Organizacionais.

\begin{abstract}
The exploratory research, summarized here, is inserted in a context of "crisis" socio. This "crisis" forwards the need for transformative change. A proposed change, added to existing, is being investigated as an alternative form of management: the Economy of Communion. Within this theme, this research is limited to an attempt of analysis of power in companies that adopt this form of management. First, it was researched, along with entrepreneurs representing a common vision to characterize the object. We performed a case study in one of the major companies that fit the concept of Economy of Communion. The method of content analysis was used to extract conclusions about the behavior of the phenomenon of power in these organizations. The summary tables produced on the interviews provide evidence to demonstrate idiosyncrasies in the exercise of the power of this new proposed management in counterpoint with the disseminated widely in the production system. Such evidence indicated the influence of the assumptions supporters of the Project on power relations, making possible an organizational practice close to what is called a radical humanist paradigm in organizational theory.
\end{abstract}

Keywords: Economy of Communion; Power; Case Study; New Organizational Models.

\title{
1 Introdução
}

A urgência por ações transformadoras (responsabilidade social corporativa, sustentabilidade, economia solidária) tem obtido destaque devido às perspectivas sociais e ambientais que, na visão de alguns estudiosos (CAPRA, 1996; EGRI; PINFIELD, 1998; SMIL, 2008), vem se agravando continuamente. Essa pesquisa se insere em um contexto em que novas formas de gestão se apresentam como alternativa aos modelos atualmente centrais. Para isso, investiga uma prática real, chamada Economia de Comunhão, que apresenta formas de gestão significativamente distintas, um modelo de gestão próprio, que sinaliza a tentativa de construção de uma nova perspectiva de atuação no sistema capitalista de produção.

Segundo Capra (1996), há consenso em diversas áreas do conhecimento quanto à condição crítica em que se encontra a sociedade moderna. É alocada às organizações parcela significativa de responsabilidade no processo de degradação socioambiental tanto pelos seus potenciais de impactos éticos e ambientais, quanto pela própria forma de management difundida nas organizações. Essas práticas defendem o interesse dos acionistas como único foco das organizações. Por consequência, pode ocorrer um afastamento de questões que não sejam puramente instrumentais e econômicas.

A Economia da Comunhão $(E d C)$ é uma experiência alternativa para os estudos organizacionais. Ela tem apresentado resultados positivos em termos de produtividade e crescimento, com formas de gestão que se diferenciam às do status quo empresarial e mais próxima a necessidades inerentes à natureza biológica humana (LEITÃO; ROUSSEAU, 2004; LEITÃO FORTUNATO; FREITAS, 2006). Trata-se de uma proposta filosófico-espiritual, oriunda da doutrina cristã, que, pelas mãos de sua líder carismática Chiara Lubich, foi replicada para a utilização na condução de empresas. Valores que visavam melhorar o nível de relacionamento entre as 
pessoas, defendendo a propagação do "amor-comportamento" - um conceito expresso na palavra grega agape, usada por Jesus Cristo - e uma distribuição de riquezas mais homogênea foram incorporados à lógica dos negócios. Isso se deve, entre outros motivos, à visão do potencial que as organizações detêm para a condução de mudanças.

A dimensão organizacional - Poder - constitui o escopo da presente pesquisa. Analisando-a, Pagès et al. (1987) afirmam que há evidências de que as relações e práticas de Poder no contexto organizacional têm gerado, ao longo de todo o período industrial, processos de dominação e fortalecimento das ligações dos indivíduos às organizações em termos econômicos, políticos, ideológicos e psicológicos. Segundo eles, tais fatos fortalecem a dicotomia capital e trabalho, implicando em problemas para esses indivíduos.

Assim sendo, o objetivo central desta pesquisa é investigar como se processam as relações de Poder em uma empresa gerida sob os preceitos da Economia de Comunhão (EdC). A seguir, será apresentado o referencial teórico que procura posicionar a pesquisa em termos de teoria. Após isso, é apresentado o método que suportou a condução da pesquisa. Por fim, a análise, quando os resultados são discutidos.

\section{Referencial teórico}

O referencial teórico trata dos conceitos da Economia de Comunhão, sua relação e impactos às organizações que estão inseridas no projeto. As principais visões do Poder no âmbito organizacional também são apresentadas e discutidas, evidenciando a lacuna de estudos sobre essa dimensão nesse tipo de organização.

\subsection{Racionalidade instrumental versus racionalidade substantiva}

É senso comum as diferenças entre os relacionamentos nos negócios dos relacionamentos humanos de outras naturezas. Tais diferenças, segundo Guerreiro Ramos (1981), residem na natureza instrumental da racionalidade utilizada pelo establishment empresarial em detrimento a uma natureza mais substantiva. A racionalidade substantiva manifesta-se pelo mérito intrínseco dos valores que a inspira sob elevado conteúdo ético (autorrealização, entendimento, julgamento ético, valores emancipatórios e autonomia). Em contrapartida, a racionalidade instrumental refere-se ao grau de acurácia com que se atingem fins, estando, assim, fundada no cálculo e na relação custo/benefício (fins, êxito/resultados, desempenho e rentabilidade). Para Guerreiro Ramos (1981), tal exacerbação da utilização da racionalidade instrumental nas organizações empresariais é causada pela força exercida pela política cognitiva centrada no mercado, ou seja, pelos valores enfatizados pelas sociedades capitalistas modernas.

Deve-se ponderar que a realidade enseja o uso de múltiplas racionalidades concomitantemente. No entanto, a ênfase na utilização do pensar instrumental pode gerar algumas disfunções, exemplificadas por acontecimentos recentes do mundo das organizações: o escândalo ENRON, os procedimentos utilizados pelas organizações americanas fornecedoras de crédito imobiliário que deram origem à crise financeira atual, desastres ambientais causados por empresas, entre outros. Isso decorre do fato de haver pouca preocupação com a questão substantiva das coisas.

A política cognitiva centrada no mercado, nos termos de Guerreiro Ramos (1981), adota, assim, uma prevalência da racionalidade instrumental conjugada com a premissa de que os interesses individuais são capazes de prover um bem-estar comum. Algumas pesquisas, como a 
de Pagès et al. (1987), constatam essas características no cerne das organizações. Tal fato pode limitar algumas características comportamentais, intrinsecamente humanas, na ação empresarial

Em contraponto, há evidências que as empresas mais avançadas na EdC - como o caso objeto deste artigo - orientam-se por uma visão dominantemente substantiva dos seus negócios (ALMEIDA, 2002). Por consequência, os conceitos da EdC se refletem em diversos aspectos de sua gestão.

Leitão e Rousseau (2004) também investigaram a prevalência de fatores substantivos em empresas de Economia de Comunhão e perceberam que essa postura passa por um processo de mudança significativamente complexo, pois se trata de modificações no entendimento da finalidade de organizações empresariais que vão contra as preconizadas comumente. Segundo Leitão e Rousseau (2004), mudanças transformadoras são de difícil aceitação e implementação. Essas mudanças requerem uma reflexão sobre o autoconhecimento, a capacidade de aprender a aprender, quando a cultura ocidental está predominantemente centrada na ação em relação à reflexão.

Nesse sentido, outros trabalhos realizados (KURTZ, 2005; SAMPAIO, 2006) em empresas da EdC defendem que a forma de gestão baseada nos princípios de cooperação e solidariedade, da liberdade e participação nas decisões e nos resultados são diferentes. Constata-se que, de fato, essas organizações trazem mudanças substanciais na lógica de entendimento e funcionamento da organização capitalista ao introduzirem uma nova perspectiva na economia liberal, com maior ênfase na cooperação e no interesse coletivo (BRUNI, 2005, p. 29).

\subsection{O projeto de economia de comunhão}

A produção bibliográfica sobre Economia de Comunhão (EdC) tem sua gênese no trabaIho seminal de Chiara Lubich ( $\mathrm{LUBICH}$, 1988; LUBICH, 2004). São textos doutrinários, que caracterizam o movimento e o projeto como um movimento social eclesial, cujos fundamentos estão nos Evangelhos e na Doutrina Social da Igreja. Sua obra foi reconhecida pela Igreja Católica e pela Academia, onde obteve títulos honorários e por organizações internacionais (LINARD, 2003).

Em seguida, surgiram contribuições de cientistas sociais, teólogos e filósofos, mas, principalmente, de economistas italianos. Esses economistas se vincularam ao movimento, examinando o projeto de EdC sob uma perspectiva teórica. Essas contribuições (BRUNI, 2002; BRU$\mathrm{NI}, 2005)$ de pesquisadores foram quase exclusivamente ensaios acadêmicos, que atendiam ao apelo de sua mentora para que ele fosse explicado teoricamente.

O projeto começou como uma prática empresarial. Tal prática tornou-se realidade, sendo integrado por empresários não vinculados ao movimento focolarino (movimento da Igreja, centrado na unidade, que oferece ao homem uma espiritualidade moderna), não religiosos ou pertencentes a outras religiões. Nesse momento, Chiara Lubich percebeu a efetividade de suas ideias e convocou a Academia para estudá-lo e foram os jovens pesquisadores que responderam primeiro a provocação de Chiara Lubich (LEITÃO; SPINELLI, 2008).

Segundo Biela (1998), o movimento dos focolares tem quatro dimensões complementares entre si: i) social; ii) moral; iii) religiosa; e vi) econômica. Desta última surgiria o projeto de economia de comunhão. O projeto foi lançado em nível mundial em Vargem Grande Paulista, São Paulo, Brasil, em maio de 1991, para ser a versão empresarial e econômica do movimento, pois, segundo Lubich (2004), era preciso levar seus princípios a uma ação concreta e transformadora. As cidades de Maria (cidadelas testemunho do Movimento Focolarino) foram os locais da instalação dos primeiros polos industriais da economia de comunhão. 
O projeto está em expansão. Como observa Linard (2003), as empresas do projeto EdC operam em mercados locais e têm sua capacidade de expansão mundial apoiada por uma rede de comunicação dos focolarinos, apta a fazer crescer de forma global o ideário do projeto. Em fins de 2006, existia mais de 820 empresas espalhadas pelos cinco continentes, a maioria com até 50 funcionários (LEITÃO; SPINELLI, 2008). Segundo os dados do Centro Filadélfia, o escritório brasileiro do projeto, situado em Vargem Grande Paulista, a Itália é o país com mais empresas registradas e com a maior produção acadêmica, seguida do Brasil. O crescimento dessas empresas no mundo, entre 1991 e 2006, foi de 13\% ao ano e, no Brasil, de 7\%.

Bruni (2005) afirma que a economia de comunhão busca uma nova relação entre o mercado e a sociedade, desafiando as ideologias dominantes nessa era de globalização. Elas são empresas privadas, inseridas no regime de mercado, que salvaguardam a propriedade privada, mas colocam o lucro em comunhão. Teriam uma visão humanista sobre a forma de gerir negócios.

Pinto e Leitão (2006), por sua vez, dizem que a diferença nessas empresas está na forma como a organização se relaciona com seus stakeholders. A diferença está na qualidade dos relacionamentos interpessoais e, principalmente, nos interorganizacionais.

A qualidade dos relacionamentos interpessoais foi pesquisada por Kurtz (2005) e por Sampaio (2006) para justificar a potencialidade dessas empresas para operarem como organizações que aprendem. As relações interpessoais são apresentadas como o elemento comportamental relevante nessas empresas e estão imbricadas no que se chama de "cultura da partilha", que tem como fundamentos o amor cristão e o princípio da espiritualidade da unidade (LUBICH, 2004).

Essa característica comportamental penetraria também todas as demais dimensões organizacionais dessas empresas, em maior ou menor intensidade, conforme suas experiências, progressos ou retrocessos na construção dessa cultura da partilha, o que se apresenta de forma desigual no conjunto dessas organizações (ALMEIDA; LEITÃO, 2003).

Contudo, apesar dos diversos trabalhos recentes sobre Economia de Comunhão (ALMEIDA, 2002; ALMEIDA; LEITÃO, 2003; KURTZ, 2005; LEITÃO; ROUSSEAU, 2004; BRUNI, 2005; PINTO; LEITÃO, 2006), nota-se uma considerável lacuna de conhecimento sobre o Poder na dinâmica organizacional dessas empresas. Acredita-se que o entendimento do comportamento da dimensão Poder é relevante para a compreensão de como são essas gestões mais substantivas ou se de fato o são.

\subsection{O fenômeno "Poder" e a Economia de Comunhão}

Segundo Galbraith (1984), a palavra poder é utilizada com frequência sem que se reflita sobre seu significado. Clegg e Hardy (2001) afirmam que a definição mais utilizada atualmente não se encontra distante das primeiras conceituações que o definem como a habilidade de fazer com que executem o que se quer, mesmo que seja contra a vontade desses executores.

Contudo, há dissonâncias entre as correntes no que tange à conceituação. A corrente estrutural-funcionalista busca desenvolver a ciência administrativa pesquisando formas de controle e regulação de eventos futuros por meio de suas causas. Por um lado, as perspectivas adotadas para os estudos sobre o Poder são para tornar cognoscível a utilização do fenômeno e para aumentar a função utilidade dos interesses organizacionais. Por outro lado, a corrente da teoria crítica e a visão pós-moderna, representada por Michel Foucault, buscam entranhar-se nas contradições e sutilezas presentes na essência do fenômeno. Foucault (1982) observa que a própria ontologia do fenômeno o caracteriza como não passível de dissecação, ou seja, 
idiossincrático, uma luta de forças hostil, e recomenda o conhecimento em suas relações mutuamente constitutivas entre o sistema estudado e o ambiente, atento à interconectividade e às formas de dominação presentes nesse ambiente. O exame do Poder não deve estar livre do contexto.

Foucault (1979) buscou analisar os mecanismos de poder e sua incidência sobre o indivíduo, concentrando-se na efetividade da ação. Ele buscou compreender a manifestação do Poder em seu menor nível, que é na relação entre indivíduos:

Quando penso na mecânica do poder, penso em sua forma capilar de existir, no ponto em que o poder encontra o próprio grânulo dos indivíduos, atinge seus corpos, vem inserir-se em seus gestos, suas atitudes, seus discursos, sua aprendizagem, sua vida cotidiana (FOUCAULT, 1979 apud MOURA, 2007, p. 12).

Esta perspectiva capilar de análise do Poder, inserida por Foucault (1979), não desmerece os atores supraindivíduos, mas foca na ação efetiva, mudando o nível de granularidade. Aceitando essa visão, o Poder não é tratado como substância ou faculdade, mas sim como a própria execução. Percebe-se, então, a essência relacional do fenômeno Poder no pensamento foucaultiano, haja vista que seu estabelecimento acontece numa relação entre indivíduos: uma ação em relação à outra ação. Para Foucault (1979), as relações de poder têm suas raízes na rede de relações que caracteriza uma sociedade. É um fenômeno relacional, por conseguinte.

As normas que tentam criar limites e definir o Poder nas organizações são, inequivocamente, variáveis a serem consideradas ao se analisar as relações entre sujeitos organizacionais. Entretanto, rejeita-se que a complexidade da presença do fenômeno Poder seja compreendida em sua completude por essas regras. Ratifica-se, então, que no discurso de Foucault (1979) o direito normativo é uma arma a ser utilizada dentro do campo de forças de Poder e não a origem única e direta do Poder de um ator organizacional.

\footnotetext{
Dessa forma, as noções dominantes de poder (que delineiam tanto abordagens modernistas quanto as funcionalistas) foram desafiadas. O Poder não era mais apenas um recurso conveniente, manipulável e determinístico. Ao contrário, todos os atores operavam dentro de uma estrutura de dominação - uma rede dominante de relações de poder - dentro da qual as perspectivas de saída eram limitadas tanto para os grupos dominantes quanto para os grupos subordinados (CLEGG; HARDY, 2001, p. 275).
}

Outra obra referencial para o desenvolvimento do presente estudo é o trabalho de Max Pagès et al. (1987). Estes autores analisam as relações de Poder entre organização e indivíduo e utilizam a dialética combinada à psicanálise como instrumento analítico de uma organização multinacional. São apresentadas profundas contradições no discurso dos respondentes nesse estudo, identificando indícios da estimulação de forças produtivas. Por um lado, isto é de incentivo a iniciativas, à atividade intelectual, à capacidade de criação e à cooperação para dar aos trabalhadores toda espécie de satisfação de ordem econômica, política, ideológica e psicológica. Entretanto e concomitantemente, outras estimulações, foram percebidas, produzindo garantia do controle, subordinação das forças produtivas dos trabalhadores aos objetivos da empresa, gerando significativos graus de angústia. Logo, a organização se depararia com uma dupla necessidade de desenvolvimentos e mediações.

Estas dualidades se desenvolvem em múltiplas formas: seria trabalhada ao nível econômico por meio de políticas de altos salários, de possibilidade de ascensão na carreira, da aceita- 
ção dos objetivos do lucro e crescimento da empresa e da aceitação do modus operandi capitalista. No nível político, seriam desenvolvidas técnicas de administração que garantam o respeito às diretrizes centrais, buscando possibilitar a iniciativa individual através de técnicas de autonomia controlada. No nível ideológico, o processo apresentaria certa doutrina dominante disseminada pela empresa, mas que encontraria variantes no corpo funcional, mesmo que sem contradições radicais ao estabelecido.

\footnotetext{
A organização funciona, por um lado, como uma máquina de prazer e, por outro lado, como uma imensa máquina de angústia. A angústia provocada pela onipresença dos controles, pelo caráter ilimitado e intangível das exigências, é compensada pelos múltiplos prazeres que a organização oferece especialmente os prazeres do tipo agressivo, o prazer de conquistar, de dominar os clientes, os colega, de se superar e de se autodominar (PAGÈS et al., 1987, p. 29).
}

Ressalte-se que as restrições de cunho político, ideológico e psicológico sempre existiram. Contudo, foi observado, no estudo de Pagès et al. (1987), uma crescente capacidade de as empresas penetrarem nos ideais, nos valores, no estilo de vida e nas estruturas de personalidade.

Tais características, encontradas na multinacional estudada por Pagès et al. (1987), aumentam a relevância de compreender o fenômeno Poder na Economia de Comunhão. Isso se deve ao fato de que as organizações de $\mathrm{EdC}$ vêm sendo descritas com tipos de gestões mais humanizadas, o que implicaria um comportamento nas relações de Poder também diferenciado.

Nesse sentido, o trabalho objetiva compreender o fenômeno Poder nessas organizações para contribuir no entendimento dessa lacuna que parece existir no conhecimento dessas organizações. Para tal, entender o Poder como uma questão relacional, no âmbito das microrrelações entre indivíduos, parece ser um enfoque adequado ao entendimento do fenômeno no contexto da Economia de Comunhão, que tanto explicita a relevância do relacionamento interpessoal na conquista dos objetivos organizacionais. A intenção é entender também se a qualidade desses relacionamentos incute uma relação diferente nas contradições entre o capital e o trabalho e nos problemas no convívio organizacional. A seguir é demonstrado como se procedeu para o alcance dos objetivos do trabalho.

\section{Metodologia do estudo}

Dentro da abordagem qualitativa, há diferentes métodos de investigação, dentre esses se encontram os Estudos de Caso (GODOY, 1995). O Estudo de Caso é um método de investigação que se caracteriza pela análise aprofundada de uma determinada realidade. Estudos de Caso são recomendados quando se colocam questões do tipo "como" e "por que", quando o pesquisador tem pouco controle sobre os eventos e quando o foco se encontra em fenômenos contemporâneos inseridos em algum contexto da vida real (YIN, 2005; AMARATUNGA et al., 2002). Segundo Dubé e Paré (2003), os Estudos de Caso são apropriados quando o objeto de investigação é complexo, é necessária uma visão do todo e quando o fenômeno estudado não pode ser analisado fora do contexto onde ocorre. Esse método de investigação também é apropriado nos casos em que é necessária profundidade na pesquisa (DUBÉ; PARÉ, 2003; EINSENHARDT, 1989). Einsenhardt (1989) argumenta e apresenta, ainda, possibilidades do Estudo de Caso para a construção de teorias. 
Pelas características apresentadas pelo Estudo de Caso e as dimensões já discutidas até o momento, esse método de investigação enquadra-se para os objetivos deste trabalho. Além disso, para Ellram (1996), o Estudo de Caso pode ser utilizado para: (1) explorar um determinado assunto ou problema, entendendo-o profundamente; (2) explanar sobre um fenômeno; (3) descrever um fenômeno; e (4) predizer características de um determinado fenômeno. Alguns dos propósitos para o uso do Estudo de Caso descrito por Ellram (1996) justificam a utilização desse método para esta pesquisa.

A presente pesquisa é caracterizada como um estudo de caso de natureza exploratória. A natureza exploratória é definida por sua aplicabilidade ao estudo de temas em novas áreas ou quando se pretende fazer emergir teoria a partir de determinada situação (ROESCH, 1999).

O estudo de campo realizado desenvolveu-se, basicamente, em duas fases. A primeira fase, por meio de um conjunto de cinco entrevistas, com duração média de 20 minutos, com empresários de economia de comunhão. A realização dessas entrevistas, de caráter exploratório, ocorreu durante a realização do Congresso Nacional de Economia de Comunhão, realizado em Vargem Grande Paulista, de 29 de abril a 10 de maio de 2007, em São Paulo. Nessas entrevistas, a abordagem foi mais conceitual, procurando-se identificar o entendimento daqueles empresários sobre as questões envolvendo decisão e relações de Poder no interior dessas organizações.

A segunda fase ocorreu através da realização de um estudo de caso, realizado numa empresa de médio porte, situada em Curitiba, PR. Tal organização é considerada de vanguarda e é consolidada como uma das maiores referências em EdC no Brasil. Já foi objeto de estudo de caso em diferentes temas em trabalhos acadêmicos importantes sobre o projeto no Brasil (GONÇALVES, 2005; PINTO; 2004). Outro fator que contribuiu para a escolha foi a disponibilidade para o desenvolvimento do estudo presencial, gentilmente concedida pelo principal empresário da empresa.

A semiestruturação das entrevistas refere-se à criação prévia de um conjunto de perguntas-guia, a partir da revisão teórica realizada, apontando para questões relacionadas à Economia de Comunhão e Poder. Além disso, procurou-se, a partir de colocações feitas pelos respondentes - Fase 1 - introduzir aspectos mais pontuais, que não haviam sido previstas no roteiro original. As entrevistas foram realizadas pessoalmente pelos autores do estudo, em julho de 2007, no ambiente da empresa. As entrevistas foram gravadas e, após, transcritas, de forma a possibilitar a análise de conteúdo e a criação de categorias de análise no momento da descrição dos resultados.

A organização escolhida foi uma distribuidora farmacêutica, sediada em Curitiba, capital paranaense. Conforme o breve histórico presente no subitem sequente, essa é uma organização considerada de vanguarda e consolidada como uma das maiores referências em EdC. Foram realizadas 16 entrevistas entre gerentes (8), funcionários administrativos (5) e operários (3), com tempo médio de 45 minutos, com o objetivo de obtenção de uma visão direta sobre as relações de Poder nessa organização. Além disso, examinaram-se também as peculiaridades da cultura organizacional que contextualiza o lócus de estudo.

Como fontes secundárias, foram acessados documentos internos da empresa, como relatórios e memorandos diversos, de forma a possibilitar aos pesquisadores a complementação de dados. Além disso, utilizou-se também o método de observação, para a obtenção das formas comportamentais identificadas durante o período de estudo.

Para análise dos dados, as entrevistas transcritas, documentos e anotações específicas dos pesquisadores foram compiladas e preparadas para o tratamento realizado no software Atlas.ti. Desenvolveu-se, com base em Bardin (1979), a técnica categorial para análise de conteúdo sobre o material das entrevistas semiestruturadas de profundidade. O estudo de caso teve 
tratamento quantitativo no inerente à análise de conteúdo (seleção e mensuração de categorias). A abordagem foi essencialmente qualitativa sobre as categorias e famílias identificadas. Cabe salientar que, pela ontologia da dimensão Poder, foi privilegiada a análise qualitativa em busca da melhor relação método-objeto. O critério adotado foi o semântico para a busca de evidências.

Para tal, definiram-se categorias oriundas das entrevistas com os empresários, Fase 1, que também foram encontradas nas falas dos respondentes do estudo de caso, Fase 2. Contudo, houve uma expansão da quantidade de categorias, em razão da maior riqueza léxica dessas últimas entrevistas.

Supõe-se que o processo de decomposição-reconstrução nesse método desempenhe uma determinada função na indicação de correspondências entre o texto analisado e a realidade subjacente. A análise de conteúdo assenta implicitamente na crença de que a categorização (passagem de dados brutos a dados organizados) não introduz desvios, por excesso ou por falta, no material, mas que revela índices invisíveis, ao nível dos dados brutos (BARDIN, 1979, p. 119).

A construção de tais sínteses e modelos segue as considerações de Demo (2000, p. 102) sobre o construtivismo, que defende que a realidade existe de maneira independente, mas não é captada como mero reflexo mecânico e direto, e sim através de um sistema perceptor e mental que a interpreta de modo construtivo. As análises aqui apresentadas, portanto, são interpretações que conferiram significados aos significantes coletados, elas não objetivam a explicação do funcionamento mecânico das coisas e nem descartam a bagagem de conhecimento e os paradigmas do pesquisador, influenciando as ilações finais. Aceita-se a ideia de equilíbrio entre a realidade agindo sobre o cérebro, e este sobre a realidade.

\subsection{Método de trabalho}

O método de trabalho desenvolvido está representado na figura 1. Primeiramente utilizou-se o referencial teórico com o objetivo de retirar questões relevantes para a montagem dos questionários.

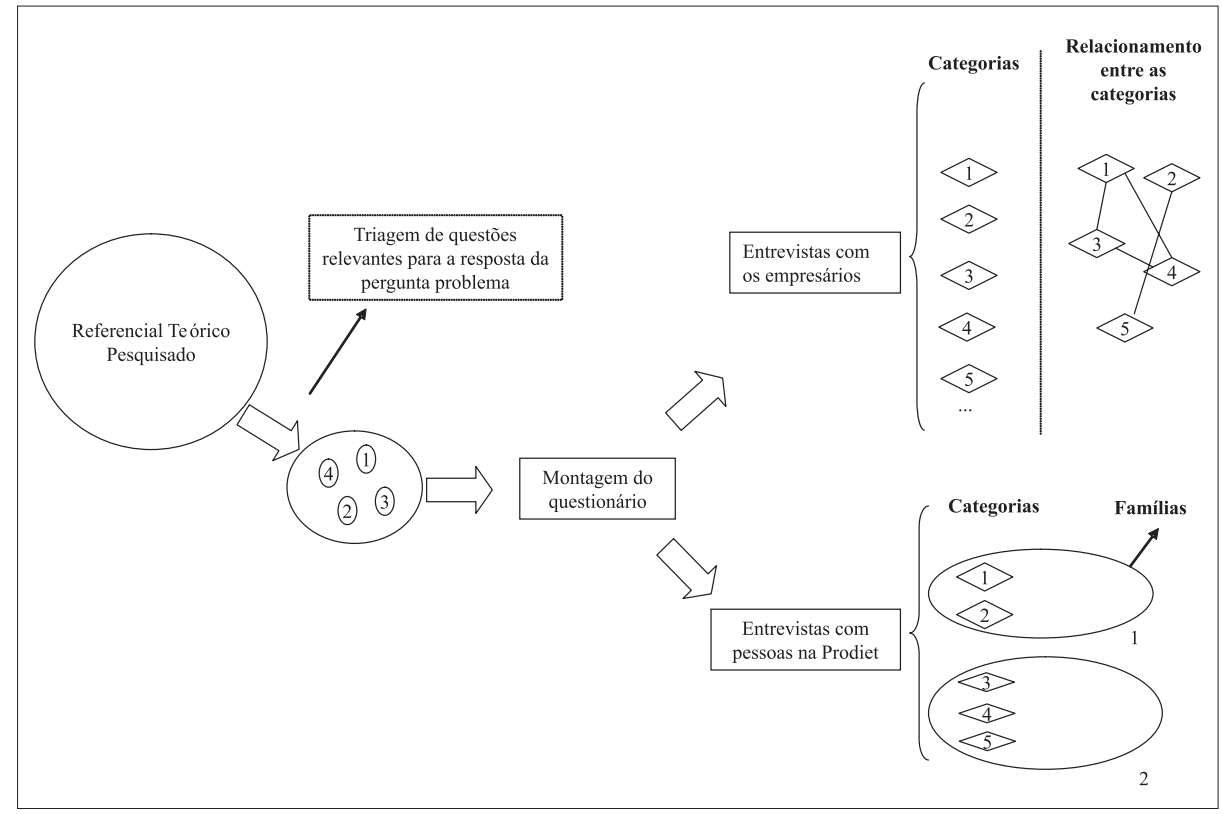

Figura 1 - O método de trabalho. 
O segundo passo foi a realização da Fase 1 da pesquisa e a análise de seus resultados. Desta fase, respeitando as regras de exclusão mútua, homogeneidade, pertinência, objetividade, fidelidade e produtividade (BARDIN, pág. 120, 1979), chegou-se às categorias "Relacionamento Interpessoal"; "Burocracia"; "Liberdade"; "Participação"; "Diálogo" e "Centralidade no Ser Humano".

O terceiro passo - e última etapa - foram as entrevistas na empresa estudada e a análise do material bruto coletado, que gerou 13 categorias expandidas, são elas: "Burocracia"; "Centralidade no Ser Humano"; "Confiança"; "Liderança"; "Liberdade"; "Oportunidade"; "Diálogo"; "Respeito"; "Participação"; "Consulta"; "Reuniões"; "Relacionamento Interpessoal" e "Ética". Como a quantidade e dados brutos coletada nesta etapa foi maior, necessitou-se de uma segundo agrupamento. Segundo Bardin (1979), este se trata do agrupamento das treze categorias em famílias por analogia de seus conteúdos; o momento da escolha dos critérios de classificação depende daquilo que se procura ou que se espera encontrar. Por tal motivo, a síntese elaborada nesse momento visa a tornar mais claro o relacionamento das 13 características interpretadas dos discursos com os trechos de maior importância do referencial teórico, facilitando a análise, a compreensão e as inferências subsequentes.

\begin{tabular}{|l|l|}
\hline \multicolumn{1}{|c|}{ Famílias } & \multicolumn{1}{c|}{ Categorias } \\
\hline Poder e aspectos burocráticos & Burocracia e Liderança \\
\hline Poder e aspectos culturais & $\begin{array}{l}\text { Centralidade no ser humano; Confiança; Liberdade; Oportunidade; Respeito e } \\
\text { Ética }\end{array}$ \\
\hline Poder e aspectos relacionais & Diálogo e Relacionamento interpessoal \\
\hline Decisão & Participação; Consulta e Reuniões \\
\hline
\end{tabular}

Quadro 1 - Categorias agrupadas por Famílias no estudo de caso.

A seguir, serão discutidos os principais resultados obtidos pela execução da pesquisa e, na sequência, as conclusões são tecidas a partir dos resultados e a confrontação com a teoria.

\section{Análise dos resultados - empresários}

A categoria "Burocracia" agrupa dizeres que enfatizam a pouca presença de mecanismos de controle e apresentou um relacionamento com a categoria "Liberdade", ilustrado na seguinte passagem: "Autoridade e estrutura hierárquica serve para manter a ordem na empresa, embora costumem ser pequenas e bastante flexíveis. E a relação entre os níveis é bastante intensa" (Empresário A).

As categorias "Burocracia" e "Relacionamento Interpessoal" se comunicam na fala dos entrevistados quando estes explicam a pequena gradação de elementos formais de padrões de comportamento. Esses elementos se fazem menos necessários devido a valores, como confiança mútua, reciprocidade e comunhão, presente nas relações entre as pessoas. O relato do Empresário C evidencia um exemplo da ligação criada entre as categorias "Relacionamento Interpessoal" e "Centralidade no ser humano": 
os sistemas de controle costumam ser bem livres, pois estão baseados nos relacionamentos pessoais [...]. Porque a empresa está para o homem, está também para trazer um conjunto de relações para que as pessoas se sintam bem em trabalhar, prazer em trabalhar. Não há divisão entre o empresário e o empregado nas relações.

A valorização do homem explicitada nos relatos de todos os entrevistados e aglutinada na categoria "Centralidade no Ser Humano" foi relacionada como condicionadora de maiores graus de liberdade ao comportamento dos funcionários em algumas passagens. Dessa forma, há uma ligação com a categoria "Liberdade".

Segundo o Empresário E, "não há divisão entre o empresário e o empregado no que tange às relações. O empresário da EdC tem que estar aberto ao diálogo". Isso proporciona a ligação entre temas componentes das categorias "Diálogo" e "Relacionamento Interpessoal".

A associação entre as categorias "Diálogo" e "Liberdade" foi encontrada em passagens como a do Empresário B, que interpreta que "no projeto nota-se menos hierarquização e mais facilidade de comunicação entre os níveis". Os relatos, de uma forma geral, sugeriram que as relações criadas entre as categorias "Liberdade", "Relacionamento Interpessoal" e "Diálogo" acabam por gerar processos decisórios consultivos ou participativos, que caracterizam a categoria "Participação". Foi salientado, ainda, que essas empresas costumam trabalhar com ambientes participativos de decisão, contudo, essa tríade ocorre em todos os níveis da organização que faz com que surjam contribuições e iniciativas. A figura 2 sintetiza graficamente uma estrutura conceitual de ligação e de centralidade das categorias inferidas.

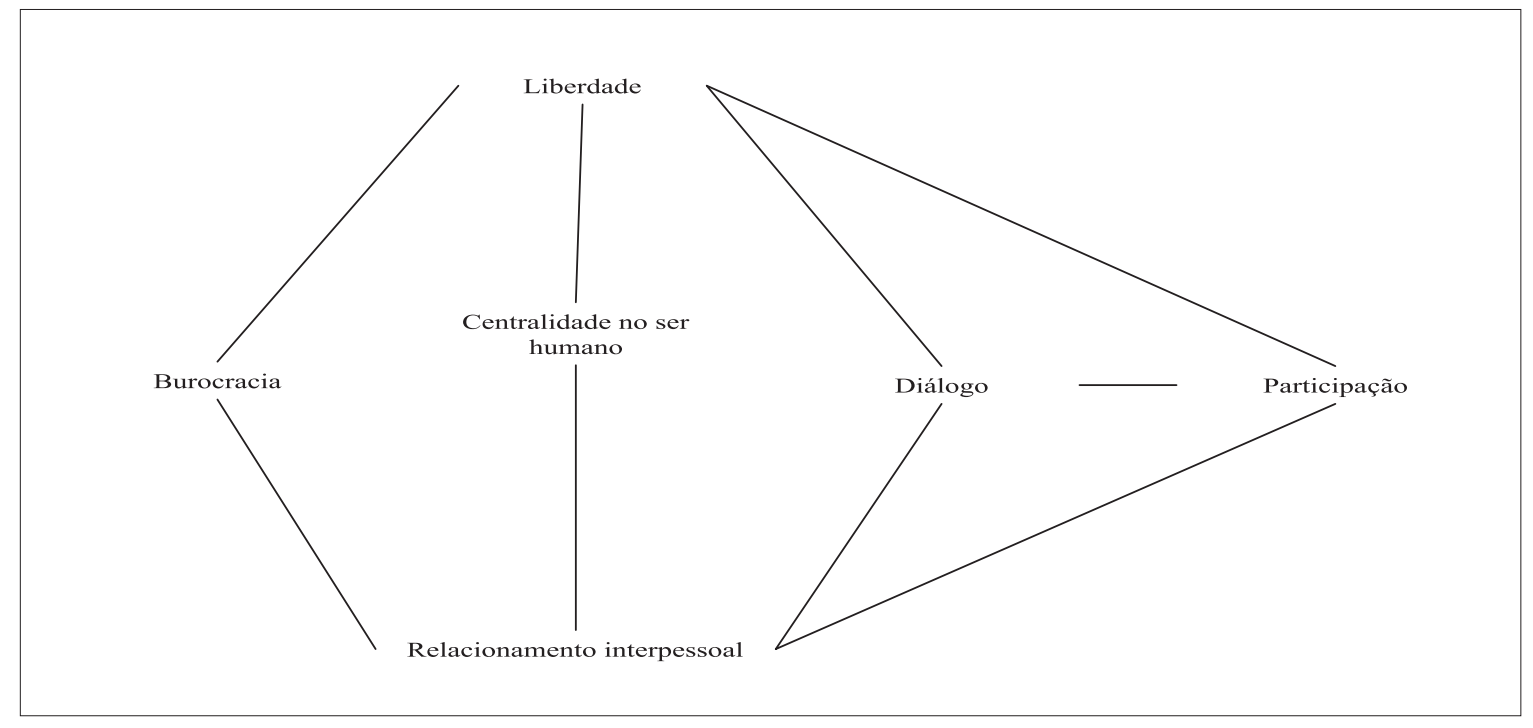

Figura 2 - Visão geral das categorias de análise e suas inter-relações.

Em síntese, as entrevistas com os empresários auxiliaram para a interpretação construtiva de um esboço conceitual para o entendimento da dinâmica das empresas de EdC. Enfatizase que tal esforço exploratório possui limitações consideráveis, haja vista o reduzido tamanho da amostra de entrevistados e a heterogeneidade das empresas participantes do projeto; todavia tais informações contribuíram tanto para a realização estudo de caso como para uma melhor preparação e condução das entrevistas. 


\section{Análise dos resultados - estudo de caso}

A organização analisada pelo estudo de caso é uma distribuidora de médio porte de produtos hospitalares e nutritivos para crianças e atletas, com mais de 500 clientes ativos no Paraná, filiais em Brasília, São Paulo e no Polo Spartaco. A empresa conta com cerca de noventa funcionários, além dos representantes. No total, dispõe de mais de cem colaboradores. Apresenta números de crescimento bastante significativos no contexto do mercado e do setor no qual atua.

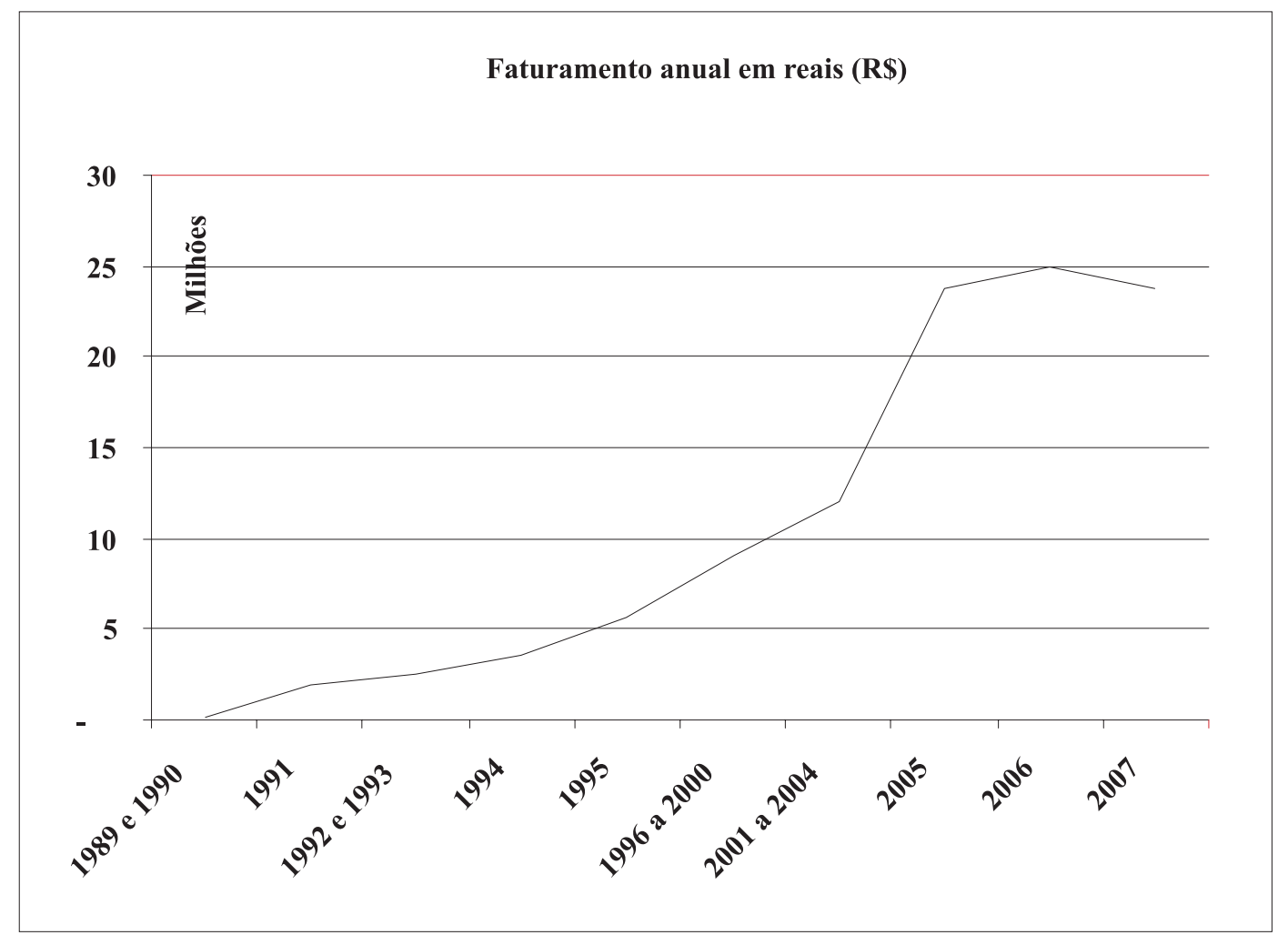

Figura 3 - Faturamento anual em R\$.

A seguir, são apresentadas as análises realizadas nas famílias que emergiram da análise das entrevistas:

- Poder e aspectos burocráticos: nota-se que a organização não preza pela instituição de artefatos burocráticos cerceadores sobre o comportamento dos atores. De acordo com as entrevistas, elas existem, mas são flexíveis. Esta condição está atrelada ao estilo de liderança carismático com que o empresário conduz a organização. Interpreta-se que esta família influencia consideravelmente as outras, pois se, por acaso, as duas categorias estivessem demonstrando formas demasiadamente formais de normatização e autoritárias de liderança, possivelmente, ter-se-ia dificuldade para a obtenção das categorias das outras famílias como estão classificadas. O relato a seguir, do empresário proprietário, retrata esta família e seus impactos nas outras: 
Bem, as normas são fundamentais a qualquer grupo da sociedade humana, na empresa não é diferente. Temos nossas normas, no entanto, essas normas são criadas por todo o grupo, não foram criadas ou copiadas de alguém que já fez. Criamos nossas próprias normas, através de uma profunda discussão com os líderes, elas me foram apresentadas no resultado do pensar coletivo, elas são fundamentais.

- Poder e aspectos culturais: por meio desse agrupamento é construída a existência dos princípios e valores do projeto de $\mathrm{EdC}$ na dinâmica organizacional da organização. Eles aparecem disseminados nos discursos de funcionários e gerentes de maneira homogênea. São apresentados, ainda, como indicadores significativos de diferenciação da organização perante o mercado e outras empresas de fora do projeto:

\begin{abstract}
As diferenças existem claramente, o modo de agir dessas pessoas parte de uma série de princípios. O respeito com as pessoas é uma das colunas que sustentam esse projeto. Respeito com seus colaboradores. Respeito não se impõe, se conquista. Respeito com seus fornecedores. Respeito pelos seus concorrentes. A empresa sempre recolhendo seus impostos, às vezes, sendo tentados a também sonegar, mas sempre cumprindo a ética. Uma ética inabalável. E nós observamos, em contrapartida, um crescimento do respeito que naturalmente causa desenvolvimento. Mas não é fácil, porque quando saímos lá fora não está escrito que esta empresa é uma empresa diferente. Enfrentamos todos os problemas ou até mais problemas do que os demais (Gerente 5)
\end{abstract}

- Poder e aspectos relacionais: as entrevistas confirmam uma qualidade especial dos relacionamentos na organização, assim como apresentado por estudos como os de Kurtz (2005) e Sampaio (2006) em outras organizações de EdC. A Gerente 7 enfatiza que:

\footnotetext{
o poder tem que ser conquistado, se você o coloca na imposição, você consegue que trabalhem daquela forma quando você estiver presente, mas se você consegue conquistálo pelo ideal da empresa, aí compromete as pessoas, se colocando à disposição enquanto líder. Aí você as ganha pelo respeito, pela admiração. A aproximação interpessoal facilita essa diferenciação.
}

- Decisão: foi percebida uma mistura de altos graus de participação durante as decisões. Quando perguntado sobre uma roda de pessoas em pé, observada pelos pesquisadores, despropositadamente, no setor de estoque, o Funcionário 5 explicou:

\footnotetext{
aquilo era uma reunião com todo o setor para acertarmos alguns problemas identificados. Quase toda a semana tem. No início era mais o gerente falando, mas agora todo mundo participa da reunião, temos abertura para colocar as ideias. Gera um espírito de grupo forte, um ajudando o outro, até porque quando um erra, todo mundo erra.
}

A figura 4 ilustra o quão complexo é a dinâmica do Poder nessa organização. Esta estrutura busca retratar o conjunto de temas presentes nas entrevistas. Por meio da figura 4, pretende-se informar que a relação íntima entre as categorias cria uma estreita composição de fatores que fornecem características diferenciadas desse conjunto de entrevistas para o conjunto de entrevistas presentes em Pagès et al. (1987). 
É importante salientar que esta estrutura guarda diferenças da estrutura conceitual da Fase 1, como era esperado. Nota-se que as citações aglutinadas nas famílias "poder e aspectos burocráticos", "poder e aspectos culturais" e "decisão" foram, significativamente, além das categorias encontradas nas entrevistas no Congresso de EdC. Tal fato sugere que a realidade organizacional da empresa supracitada já apresenta idiossincrasias em relação ao que os empresários conceituaram como forma das empresas de EdC, em média, portarem-se.

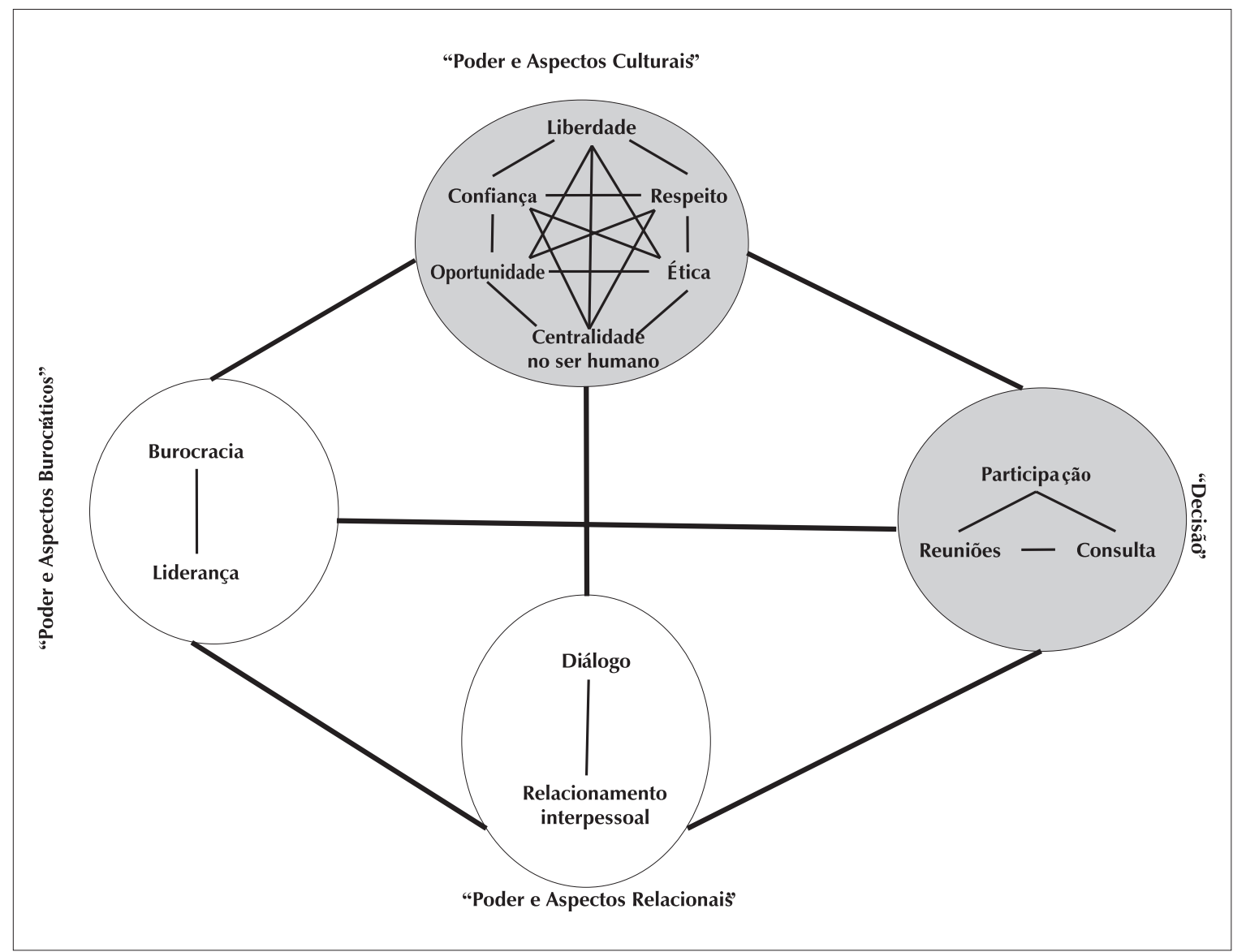

Figura 4 - Agrupamento em famílias.

Foram identificadas duas ações em curso na organização: a ênfase no programa de certificação ISO e o que se denominou de tentativa de blindagem do proprietário a problemas que, segundo os entrevistados, poderiam ser resolvidos nas gerências. Essas ações são relevantes porque tendem a mudar a configuração do quadro presente na figura 4.

Sobre a padronização via programa de certificação, percebeu-se grande ênfase dada pelos pesquisados do nível estratégico a essa ação enquanto prioridade organizacional. E, em seus próprios discursos e trejeitos corporais, notava-se uma preocupação em salientar que tal aumento de controle sobre os processos visava tão somente o aumento da eficiência operacional. Possivelmente, porque sabem que a medida para que esse aumento de padrão dos processos não ocasione em mudanças excessivas em temas da família "poder e aspectos burocráticos" não é tão trivial. Segundo interpretação dos pesquisadores, esta possível mudança drástica em normas que busquem enfatizar o grau de hierarquização da organização impactaria nas outras duas famílias relacionadas ao fenômeno poder, podendo aumentar o nível de formalização das relações e, consequentemente, também mexeriam no modelo de processo decisório que será praticado na organização. 
De forma parecida, a ação de blindagem do Diretor a contatos com funcionários que poderiam ser realizados e, quiçá, resolvidos pelas gerências intermediárias pode gerar, futuramente, mudanças profundas no quadro diagnosticado. Vislumbram-se duas possibilidades nesse caso

Por um lado, a forma de liderança exercida pelo empresário, observada e relatada pelos funcionários do nível tático-operacional, poderia mudar caso os gerentes não conseguissem imprimir um estilo de condução próximo ao que o Diretor deteve durante o crescimento da organização. Este ponto é crucial porque a frequência de elogios à conduta do proprietário condicionou a análise de que a conformação apresentada no discurso à categoria "liderança" dissemina os valores e princípios do Projeto, portanto, tem impacto considerável nos relacionamentos interpessoais e, em consequência, nas relações de poder e na tomada de decisão da organização.

Por outro lado, foram notados alguns elogios à forma de gestão dada para alguns gerentes intrasetorialmente em termos de liderança e abertura à participação. Logo, há indícios de que esses gerentes poderiam ser multiplicadores mais abrangentes dos conceitos da EdC na organização se desenvolvessem condutas aproximadas às do Diretor ou condizentes com as ideias preconizadas por ele.

\section{Conclusões}

O trabalho aqui apresentado objetivava compreender as características dos fenômenos poder e decisão em empresas de Economia de Comunhão, a fim de verificar se ali, estes também se manifestavam em formas opressoras e manipuladoras, tal como verificado em estudos de Pagès et al. (1987) em empresas modernas.

Apesar de certa homogeneidade encontrada nas respostas, o que permitiu o encontro a certas peculiaridades nas relações de poder e seus impactos em decisões, os depoimentos deixam perceber a existência de um processo constante de aprendizado na empresa, com vistas às metas e princípios de $\mathrm{EdC}$, o que deve possibilitar dúvidas, desvios ou erros que são confrontados no dia a dia com aqueles princípios, numa relação dialética que leva a um constante aprender/mudar. Portanto, nota-se que eles buscam a evolução num suposto "modelo ótimo" de gestão e de EdC, todavia reitera-se que esses ápices, inerentemente, não existem nem para a gestão, nem para a Economia de Comunhão.

O quadro conceitual conseguido por meio da análise de conteúdo dos depoimentos dos cinco empresários apontava para um arranjo que precipitou uma série de pontos especiais. Não desconsideramos as limitações que essa interpretação conceitual em cima de uma amostra reduzida de participantes do Projeto contém, mas pensamos que as conclusões parciais desta análise serviram para o levantamento de discursos homogêneos, apresentando características que ajudam à resposta de parte da pergunta problema.

As duas análises de conteúdo realizadas evidenciam que estas organizações buscam realizar gestões diferenciadas em cima de pilares ideológicos próprios que convivem com a competição do mercado. Elas demonstram que, devido à valorização menos acentuada da hierarquia, seria apenas pelo entendimento da dinâmica relacional ampliada entre os indivíduos da organização que se encontraria e poderia compreender o Poder. E as relações se mostram, de fato, diferenciadas tanto no modelo idealizado como nos depoimentos do estudo de caso. 
Apesar da qualidade das relações focar-se mais nas categorias "relacionamento interpessoal", presente nos dois estudos, e na família "poder e aspectos relacionais", encontrada no estudo de caso, há uma nítida tendência nos relatos de influências mútuas entre os agrupamentos, além de interseções e sobreposições que foram desconsideradas para efeito de análise e ilustração das interpretações, mas estão sinalizados por meio das ligações entre as categorias e famílias. É importante confirmar que esta parcialização linear não existe, é apenas um esforço para facilitar a análise e que, por consequência, gera a conclusão que a interdependência de vários dos fatores explicitados proporciona a presença diferenciada desses fenômenos nessas organizações.

Eis um dos principais pontos há se considerar e que pode ocasionar em mudanças impactantes no quadro de categorias e relações apreendidas no estudo de caso, pois as ações identificadas e com potencial de mudança têm ligações diretas com as categorias. O problema não é mudar, pois isso é necessário e inevitável, a questão é se os princípios que privilegiam as necessidades humanas presentes na organização serão protegidos perante a nova dinâmica relacional.

Cabe ainda observar que aquilo que se constata na cultura EdC se mostra antagônico à dominação e à exploração de pessoas. Além de não valorizar a formação de um ambiente predatório e, mesmo não sendo a questão ambiental o alvo principal do exame, os depoimentos confirmam essa ideia exposta pelos principais autores do assunto.

Outro ponto que não pode ser negligenciado é a visão das pessoas sobre o lucro. Porque é bem disseminada a ideia de que tudo é feito com o auxílio do excedente financeiro, que proporciona o reinvestimento no negócio, a formação de uma nova mentalidade empresarial e a doação de parte desse lucro para um fundo de pobreza, objetivos do projeto de EdC. A comunhão, em nível econômico, é muito dependente e agradecida ao lucro. Contudo, o alvo principal dessas organizações aparenta ser, de fato, o ser humano.

A passagem abaixo extraída do depoimento do Diretor-proprietário se aproxima muito do exposto por Leitão, Fortunato e Freitas (2006) quando da associação entre necessidades intrínsecas ao ser humano e a participação dos trabalhadores em prol da organização. É enfatizado que seria mais adequado procurar receber o máximo do ser humano, não desconsiderando sua condição de ser humano, o que sintetiza muitos aspectos diferenciais que essas empresas têm e proporcionam reflexões de múltiplas naturezas:

O poder, dentro de uma organização, está diretamente ligado à cultura da organização. E na cultura da EdC, onde a ideia é partilhar, o diretor não toma decisões sozinho. Onde tudo é partilhado, ele não se coloca numa posição de dono da verdade, mas apenas de líder do grupo. Nasce uma nova cultura, um novo trabalhador que se sente livre e a criatividade aflora. Normalmente, a falta de liberdade torna as pessoas menos criativas. A pessoa livre é aquela pessoa que aflora dela toda sua criatividade. A minha empresa está em construção. A minha empresa ainda é jovem, apenas 18 anos, não nasci empreendedor, muito menos empresário, aprendo todos os dias, mas fazer uma gestão participativa, não por princípios democráticos, mas sim por respeito ao ser humano, isto é a cultura da reciprocidade. Quando uma pessoa tem uma grande ideia e esta ideia é colocada em prática, ela compra a ideia e se compromete. (Diretor).

Por fim, não foram percebidos mecanismos sutis de dominação ou manipulação das pessoas, conforme apresentado por Pagès et al. (1987). Logo, conclui-se que a pesquisa demonstra haver aspectos diferenciados no que tange às práticas de poder, presentes nas sínteses 
desenvolvidas pelas análises de conteúdo. Essas primeiras conclusões sugerem que este estudo deve ser continuado, na busca de maior generalização sobre se a qualidade dos relacionamentos interpessoais impactam as relações de poder e, quando combinadas com técnicas de gestão subordinadas a esses valores, se podem produzir vantagens competitivas.

No que tange a pesquisas futuras nesse tema, considera-se, ainda, que esse estudo abre caminhos para outras pesquisas no sentido de buscar generalizações nas conexões e construtos apresentados. Acredita-se que, após esta exploração que proporcionou essas dimensões (categorias), poder-se-ia caminhar para a realização de levantamentos quantitativos, visando à comprovação empírica desses dados.

\section{Referências bibliográficas}

AMARATUNGA, D. et al. Quatitative and qualitative research in the built environment: application of "mixed" research approach. Work Study, Emerald, v. 51, n. 1, p. 17-31, 2002.

ALMEIDA, M. A. As empresas de economia de comunhão: possibilidades de valorização da racionalidade substantiva na organização econômica? Dissertação (Mestrado em Administração)Pontifícia Universidade Católica do Rio de Janeiro, Rio de Janeiro, 2002.

ALMEIDA, M. A.; LEITÃO, S. P. Empresas de economia de comunhão e razão substantiva. Revista de Administração Pública (RAP), Rio de Janeiro, v. 6, p. 1146-1170, 2003.

BARDIN, L. Análise de conteúdo. Lisboa: Edições 70, 1979 .

BIELA, A. Uma revolução "copernicana" para as ciências sociais. In: COSTA et al. Economia de comunhão. São Paulo: Cidade Nova, 1998.

BRUNI, Luigino. Comunhão e as novas palavras. São Paulo: Cidade Nova, 2005.

Economia de comunhão. Vargem Grande Paulista: Cidade Nova, 2002.

CAPRA, F. A teia da vida: uma nova compreensão científica dos sistemas vivos. São Paulo: Cultrix, 1996.

CLEGG, S. R.; HARDY, C. Alguns ousam chamá-lo de poder. In: CLEGG et al. Handbook de estudos organizacionais. São Paulo: Atlas, 2001. v.2.

DEMO, P. Conhecer \& aprender: sabedoria dos limites e desafios. Porto Alegre: Artes Médicas Sul, 2000.

DUBÉ, L.; PARÉ, G. Rigor in information systems positivist case research: current practices, trends and recomendations, MIS Quaterly, v.27, n.4, p.597635, 2003.

EGRI, C.P.; PINFIELD, L.T. As organizações e a biosfera: ecologia e meio ambiente. In: CLEGG et al. Handbook de estudos organizacionais. São Paulo: Atlas, 1998. v.1.

EINSENHARDT, K. M. Building theories from case study research. Academy of Management Review, Stanford, v.14, p.532-550, 1989.

ELLRAM, L. M. The use of the case study method in logistics research. Journal of Business Logistics, Arizona, v.17, n.2, p.93-138, 1996.

FOUCAULT, M. Microfísica do poder. Rio de Janeiro: Graal, 1979.

The subject and power. In: DREYFUS, M.L; RABINOW, P. (Coord.). Michel Foucault beyond structuralism and hermeneutics. Chicago: The University of Chicago Press, 1982. p. 208 - 228

GALBRAITH, J. K. Anatomia do poder. São Paulo: Pioneira, 1984.

GODOY, A. S. Pesquisa qualitativa: tipos fundamentais. RAE - Revista de Administração de Empresas, v.35, n.3, p.20-29, 1995.

GONÇALVES, H. H. B. A experiência dos pioneiros da economia de comunhão na liberdade no primeiro decênio (1991-2001) no Brasil: absurdo e graça da mudança de mentalidade do empresário. 
2005, 348f. Tese (Doutorado em Engenharia de Produção)-Coordenação dos Programas de Pós-Graduação de Engenharia - COPPE, Universidade Federal do Rio de Janeiro, Rio de Janeiro, 2005.

KURTZ, R. G. M. Relacionamentos interpessoais e aprendizagem organizacional na economia de comunhão. Dissertação (Mestrado em Administração)-Pontifícia Universidade Católica do Rio de Janeiro, Rio de Janeiro, 2005.

LEITÃO, S. P.; ROUSSEAU, K. Introdução à natureza da mudança transformadora nas organizações na perspectiva da biologia cognitiva. Revista de Administração Pública (RAP), v. 38, n. 5, p. 683-710, set./out. 2004.

LEITÃO, S. P.; FORTUNATO, G.; FREITAS, A. S. Relacionamentos interpessoais e emoção nas organizações: uma visão biológica. Revista de Administração Pública, v.40, n.5, p. 883-907, set./out. 2006.

LEITÃO, S. P.; SPINELLI, R. A. Economia de comunhão no Brasil: a produção acadêmica em administração entre 1991 e 2006. Revista de Administração Pública, v. 42, n.3, mai./jun. 2008.

LINARD, K.T. Economy of communion: sistemic factors in the rise of a new entrepreneurship. Systems Research and Behavioral Science, n.20, p.163-175, 2003.

Chiara Lubich e o movimento dos focolares. São Paulo: Cidade Nova, 1988.

Economia de comunhão: história e profecia. São Paulo: Cidade Nova, 2004.

MOURA, João C. A. Q. de. O poder na obra de Foucault e as estratégias do contemporâneo. 2007, 85f. Dissertação (Mestrado EM PSICOLOGIA)Pontifícia Universidade Católica do Rio de Janeiro, Rio de Janeiro, 2007.

Departamento de Psicologia da PUC - Rio, Rio de Janeiro, Brasil, 2007.

PAGÈS, M. et al. O poder das organizações. São Paulo: Atlas, 1987.
PINTO, Mário C. Soares. A economia de comunhão sob o olhar da teoria dos stakeholders. 2004. 452f. Tese (Doutorado em Administração de Empresas)Pontifícia Universidade Católica do Rio de Janeiro, Rio de Janeiro, 2004.

PINTO, M. C. S.; LEITÃO, S. P. Economia de comunhão, empresas para um capitalismo transformado. Rio de Janeiro: Fundação Getúlio Vargas, 2006.

RAMOS, Alberto Guerreiro. A nova ciência das organizações. Rio de Janeiro: Fundação Getúlio Vargas, 1981.

ROESCH, S. M. A. Projetos de estágio e de pesquisa em Administração: guia para estágios, trabaIhos de conclusão, dissertações e estudo de caso. 2. ed. São Paulo: Atlas, 1999.

SAMPAIO, M. A. L. Economia de comunhão e o conceito de organização de aprendizagem. Dissertação (Mestrado), em Administração)-Pontifícia Universidade Católica do Rio de Janeiro, Rio de Janeiro, 2006.

SMIL, V. Global catastrophes and trends: the next fifty years. Cambridge: MIT Press, 2008.

YIN, R. K. Estudos de caso: planejamento e métodos. 3. ed. Porto Alegre: Bookman, 2005. 